\section{Brown deposits in the optic of foldable intraocular lenses in patients with uveitis}

\author{
Abstract \\ Purpose To report a new finding of brown \\ deposits scattered in the substance of the optic \\ of foldable intraocular lenses (IOL) following \\ phakoemulsification in patients with uveitis. \\ Methods Consecutive uveitis patients (54 \\ patients, 71 eyes) who had undergone \\ phakoemulsification with a foldable posterior \\ chamber IOL between March 1996 and \\ November 2000 were studied. A variety of \\ biomaterials from seven different \\ manufacturers had been implanted. One \\ masked observer using slit-lamp \\ biomicroscopy assessed deposits in the \\ substance of the optic of the \\ IOL.
}

The Birmingham and Midland Eye Centre Birmingham, UK

\section{Correspondence:}

PI Murray

Academic Unit of Ophthalmology

Division of Immunity and Infection Birmingham and Midland Eye Centre Sandwell and West Birmingham Hospitals NHS Trust, City Hospital Dudley Road

Birmingham B18 7QU, UK

Tel: +441215076851

Fax: +44121507 6853

E-mail: P.I.Murray@

bham.ac.uk

Received: 13 August 2002 Accepted: 20 December 2002

Financial support: Nil Proprietary interest: Nil

Presented as a poster at the Association for Research in Vision and Ophthalmology 2001 Annual Meeting, Fort Lauderdale, Florida
Results Brown deposits were detected in the substance of the optic of 25/71 (35\%) IOLs with 18/22 (82\%) of AcrySof MA60BM IOLs being affected. Using logistic regression analysis, the AcrySof MA60BM IOL was significantly associated with the presence of deposits (adjusted odds ratio $=38.5,95 \%$ CI 6.9-200, $P<0.001)$. Using multiple regression analysis, there was a significant association between the severity of deposits and the use of the AcrySof MA60BM IOL $(P=0.005)$. Compared with other foldable IOLs implanted, the AcrySof MA60BM IOL was 38.5 times more likely to develop intra-IOL deposits. There was no association with those eyes that had undergone increased intraocular manipulations. The deposits did not appear to affect visual acuity.

Conclusions To our knowledge the finding of brown intra-IOL deposits has not previously been described. These deposits are more frequent in the AcrySof MA60BM implant than the other foldable implants studied. They share some similarities with glistenings, but their exact nature remains unknown.

Eye (2004) 18, 54-58. doi:10.1038/sj.eye.6700506
K Manuchehri, S Mohamed, D Cheung, T Saeed and PI Murray

Keywords: uveitis; phakoemulsification; intraocular lens; deposits

Introduction

Cataract surgery with intraocular lens (IOL) implantation in uveitis patients is now accepted to be a successful procedure. Many published series have reported excellent visual results after extracapsular cataract extraction with a rigid one-piece $\mathrm{IOL}_{,}{ }^{1-3}$ as well as phakoemulsification using a foldable IOL. ${ }^{4,5}$ This has been because of a combination of an improvement in microsurgical techniques including small incision surgery, the appropriate timing of the surgery, and adequate pre-, periand postoperative control of the intraocular inflammation. The biocompatibility of IOLs, or their ability to remain inert and minimise host reactions, is also of paramount importance.

IOL implantation triggers a number of reactions including foreign body and inflammatory responses, and complement and coagulation cascades. ${ }^{6-9}$ This leads to cellular adhesion on the anterior surface of the implant and proliferation of lens epithelial cells resulting in posterior capsule opacification and anterior capsule phimosis. ${ }^{10}$ Not only will these responses be heightened in eyes prone to intraocular inflammation, the clarity of the optic will also be jeopardised. Giant cell and pigmentary deposits on the surface of the optic are frequently encountered in uveitic eyes, and recently surface opacification of foldable silicone IOLs in the form of crystalline deposits has been described following surgery for agerelated cataract. ${ }^{11-14}$ Changes within the substance of the optic are unusual, but have previously been reported as glistenings or vacuoles in the AcrySof MA60BM (Alcon Surgical, UK) foldable IOL, ${ }^{15-20}$ transient fogging of AcrySof $\mathrm{IOL}_{r}{ }^{21}$ and late clouding of a foldable acrylic IOL (SC60B-OUV Medical Devices Research, FL) ${ }^{22}$ as well as hydrogel IOLs. $^{23}$ 
At a routine visit to our uveitis clinic, a pseudophakic patient was noted to have brown deposits resembling iris pigment scattered throughout the optic of his foldable IOL. After a MEDLINE and EMBASE literature search failed to reveal a similar case, we decided to review uveitis patients who had previously undergone phakoemulsification with a foldable IOL to assess the prevalence of this finding.

\section{Methods}

The study was designed to be a cross-sectional prevalence study to ascertain possible risk factors for the presence of brown deposits in foldable IOLs in patients with uveitis. We prospectively examined all eyes of consecutive pseudophakic patients with foldable IOLs attending the Uveitis Clinics at the Birmingham and Midland Eye Centre between October 2000 and May 2001. All patients examined were included in the study.

Brown deposits within the substance of the optic (in future referred to as intra-IOL deposits) were assessed using slit-lamp biomicroscopy by a single observer (PIM) masked to the type of IOL implanted. The degree of deposits in the IOL was estimated as none, mild, moderate, or severe. The grading was performed by counting the number of pigment deposits present in a standard slit beam of $3 \mathrm{~mm}$ high $\times 2 \mathrm{~mm}$ wide. Mild cases had between one and 10 pigment deposits, moderate between 11 and 30, and severe cases had greater than 30 per standard slit beam.

The variables tested included age, sex, race, International Uveitis Study Group (IUSG) classification, aetiology of the uveitis, severity of postoperative uveitis, time between the date of operation and the assessment date, intraoperative manipulations or complications that may have increased iris pigment dispersion, and make of IOL. Data were collected in a two-stage process. Firstly, the degree of intra-IOL deposits was graded by a masked observer (PIM). Secondly, the variables described above were then collected by case note review by the other authors. Data were analysed using the SPSS statistical package. Multivariate analysis was applied to determine which variables were significantly associated with the presence and severity of the deposits.

\section{Results}

In total, 71 eyes of 54 patients who had undergone surgery between March 1996 and November 2000 were included in the study. A variety of foldable IOLs of different biomaterials from various manufacturers had been implanted (Table 1).

Patients were aged between 21 and 87 years of age (mean 50 years, $\mathrm{SD} \pm 17$ years). A total of 20 patients
Table 1 Type of intraocular lens biomaterial implanted

\begin{tabular}{ll}
\hline Intraocular lens & \\
\hline Alcon Acrysof MA60BM & Biomaterial \\
Rayner Raysoft 574H/ & Hydrophobic acrylic \\
Centerflex 570H & Hydrophilic acrylic \\
Storz Hydroview H60M & Hydrophilic acrylic/hydrogel \\
Allergan AR40 & Hydrophobic acrylic \\
Chauvin akreos fit & Hydrophilic acrylic \\
Pharmacia 911A/912 & Hydrophobic silicone \\
Allergan SI30NB/SI40NB & Hydrophobic silicone \\
\hline
\end{tabular}

a'Some of the implants have the same optic but a different model number because of a change in the haptic and these have been grouped together.

$(37 \%)$ were men and $34(63 \%)$ were women. Among them, $34(63 \%)$ patients were Caucasian, 19 (35\%) of Indo-Pakistani origin, and one (2\%) African-Caribbean. The mean time from surgery to date of assessment was 23 months (range 1-56 months).

A total of 25 patients had panuveitis (this included six patients with sarcoidosis, two with toxocariasis, two with Behcet's disease, two with acute retinal necrosis, one with toxoplasmosis, and one with systemic lupus erythematosus). A total of 18 had anterior uveitis (including four with HLA-B27-associated disease, one with sclerouveitis secondary to rheumatoid arthritis, one herpesviral, and one with diabetes mellitus-related uveitis); one patient had intermediate uveitis with no systemic disease association. There were 10 patients with Fuchs' heterochromic cyclitis.

Two procedures $(3 \%)$ were complicated by vitreous loss, and six eyes (9\%) had complications that may have caused increased pigment dispersion. These included three eyes where iris prolapsed out of the side-port incision, one case of iris trauma from the phakoemulsification probe, one postoperative bacterial endophthalmitis that required vitreous biopsy and intravitreal antibiotics, and one case of pupil block needing a surgical peripheral iridectomy 3 weeks after the phakoemulsification. In all, 32 cases (43\%) had additional intraoperative manipulations that may have caused increased pigment release. These included synechiolysis, division of pupillary membranes, use of iris retractors, sphincterotomies, and peripheral iridectomies.

A total of $25(35 \%)$ of the 71 eyes had some degree of brown intra-IOL deposits. These were classified as mild in nine $(13 \%)$, moderate in nine $(13 \%)$, and severe in seven $(10 \%)$ eyes. In each patient, the deposits were diffusely scattered throughout the optic of the IOL (Figure 1a-c). Although easily seen on the slit lamp, the deposits were very difficult to photograph.

The association between degree of intra-IOL deposits and type of biomaterial is shown in Table 2. Intra-IOL 

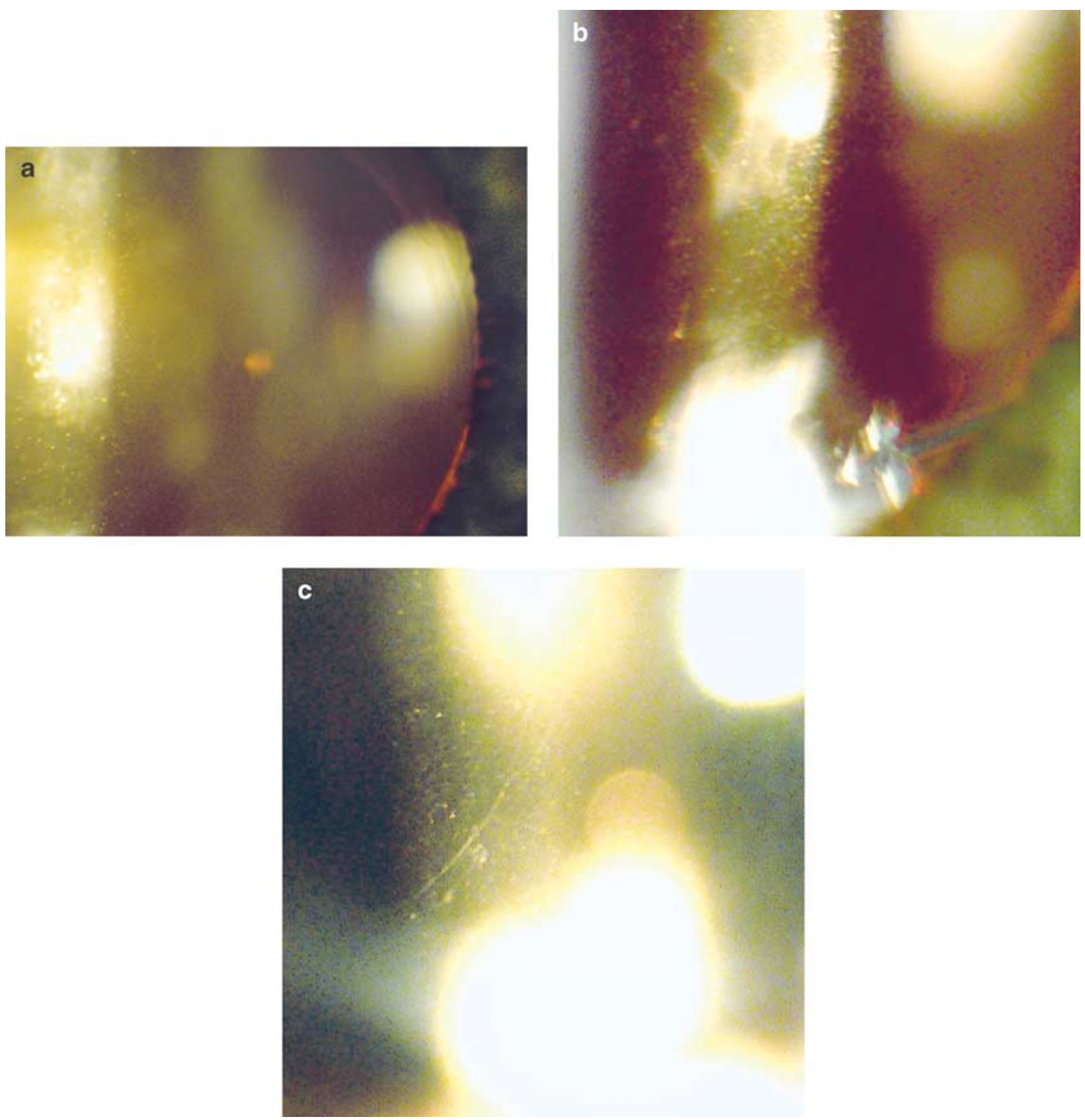

Figure $1(\mathrm{a}-\mathrm{c})$ Deposits in the optic of AcrySof lenses.

deposits were most commonly seen in the AcrySof MA60BM lens $(18 / 22,82 \%, P<0.001)$ and in the greatest severity $(P=0.005)$. Even in the most severe cases, the deposits did not appear to affect visual acuity (Table 3).

Using single-entry linear regression analysis, we found that both the make of IOL and the number of months between the date of operation and the date of assessment were significantly associated with the degree of intra-IOL deposits ( $P=0.001$ and 0.027 , respectively). However, using multiple regression analysis, we found only the make of IOL to be statistically significant $(P=0.005)$. Finally, using logistic regression analysis, there was a definite association between the AcrySof MA60BM lens and the presence of intra-IOL deposits (adjusted odds ratio $=38.5$, 95\% CI 6.9-200, $P<0.001$ ). Furthermore, this IOL was on average 38.5 times more likely to have intra-
IOL deposits than the other types of foldable IOLs used in this study.

\section{Discussion}

Various deposits including pigmentary deposits have previously been described on the surface of IOLs. ${ }^{24} \mathrm{We}$ report a new finding of intra-IOL deposits in the optic of foldable IOLs in patients with uveitis. The deposits were diffusely scattered throughout the whole substance of the optic. The majority of IOLs affected were of the AcrySof MA60BM lens type, with this lens being 38.5 times more likely to have intra-IOL deposits than the other types of foldable IOLs used. Nevertheless, it occurred to various degrees in all the IOLs that we examined, except the Storz Hydroview $(n=7)$, Allergan AR40 $(n=3)$, and the 
Table 2 Frequency of deposits in the various types of intraocular lens

\begin{tabular}{|c|c|c|c|c|}
\hline Intra-ocular lens type & $\begin{array}{c}\text { No } \\
\text { deposits }\end{array}$ & $\begin{array}{c}\text { Mild } \\
\text { deposits }\end{array}$ & $\begin{array}{c}\text { Moderate } \\
\text { deposits }\end{array}$ & $\begin{array}{l}\text { Severe } \\
\text { deposits }\end{array}$ \\
\hline $\begin{array}{l}\text { Alcon Acrysof MA60BM } \\
(n=22)\end{array}$ & 4 & 6 & 6 & 6 \\
\hline $\begin{array}{l}\text { Rayner Raysoft 574H/ } \\
\text { Centerflex 570H ( } n=19)\end{array}$ & 17 & 1 & 1 & 0 \\
\hline $\begin{array}{l}\text { Storz Hydroview H60M } \\
(n=7)\end{array}$ & 7 & 0 & 0 & 0 \\
\hline Allergan AR40 $(n=3)$ & 3 & 0 & 0 & 0 \\
\hline Chauvin Akreos Fit $(n=2)$ & 2 & 0 & 0 & 0 \\
\hline $\begin{array}{l}\text { Pharmacia 911A/912 } \\
(n=10)\end{array}$ & 7 & 1 & 1 & 1 \\
\hline $\begin{array}{l}\text { Allergan SI30NB/SI40NB } \\
(n=8)\end{array}$ & 6 & 1 & 1 & 0 \\
\hline
\end{tabular}

Table 3 Relation between degree of deposits and final visual acuity in 71 eyes

\begin{tabular}{lcccc}
\hline Degree of deposits & $\geqslant 6 / 9$ & $6 / 12-6 / 18$ & $6 / 24-6 / 60 a$ & $<6 / 60^{a}$ \\
\hline None & 25 & 12 & 5 & 4 \\
Mild & 5 & 2 & 1 & 1 \\
Moderate & 3 & 2 & 2 & 2 \\
Severe & 4 & 2 & 1 & 0 \\
\hline
\end{tabular}

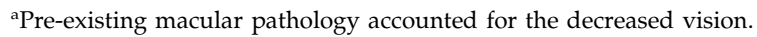

Chauvin Akreos Fit $(n=2)$ lenses. This may be because of the small number of these lenses used in this study.

Although the time from surgery to examination appeared to show a statistically significant association with the severity of deposits, this was not the case when using multiple regression analysis. Also, it was difficult to know exactly when these deposits started to appear. It is possible that they were present at an earlier date but had been missed by the examining ophthalmologist at that time.

The deposits did not appear to affect visual acuity even in the severest cases. Further tests of visual function were not performed, as it would have been difficult to ascertain if any abnormalities would have been as a result of the deposits or because of the associated posterior capsular opacification, vitreous opacification, and macular changes commonly seen in this group of patients.

Changes to the optic of IOLs are well recognised, particularly in foldable IOLs. Intraoperative crystallisation occurring on the surface of the IOL has been described and has been associated with Healon GV and silicone foldable IOLs (especially the Allergan SI130 and Chiron 32-C10XX IOLs), ${ }^{11}$ and use of BSS plus. ${ }^{12}$ Crystallisation has also been described under the anterior and posterior lens surfaces in PMMA IOLs, but visual acuity does not seem to be affected in these cases. ${ }^{13}$
Recently, a case report describing opalescence of a hydrogel intraocular implant has been described. ${ }^{23}$ The appearance of this phenomenon is quite different from what we have observed in that the opalescence tends to affect mainly the surface rather than the substance of the implant. Acrylic and silicone lenses also seem to be prone to opacification. ${ }^{14,22}$

Many reports concern deposits on the AcrySof IOL itself. One particular report describes changes on the anterior surface of the AcrySof IOL, which is thought to be caused by the proliferation of the lens epithelial cells from the capsulorrhexis margin. ${ }^{25}$ More recently, 'glistenings' or 'vacuoles' have been described in the optic in relation to acrylic ${ }^{15}$ and, in particular, have been reported in up to $93 \%$ of AcrySof IOLs. ${ }^{15-20}$ A prevalence of nearly $60 \%$ glistening formation has been shown 4-22 months postoperatively in 144 patients with AcrySof IOLs (K Mitooka et al, poster presented at the Symposium on Cataract, IOL and Refractive Surgery, Seattle, USA, April 1999). These glistenings, comprising small refractive opacities, were initially thought to be related to the type of packaging used for the IOL, and may be temperature dependent. ${ }^{18}$ They are believed to be vacuoles formed within the substance of the optic and have been shown in vitro to be in proportion to the quantity of lipids and proteins in the solution bathing the IOL. ${ }^{18}$ Nevertheless, our deposits were dissimilar to the published reports on glistenings, and they were found in other IOL biomaterials, including silicone.

Ideally, a control group of nonuveitis patients would have been useful to see if uveitis per se was a factor in deposit formation. Unfortunately, the AcrySof IOL is not the standard IOL used in routine phakoemulsification in our institution. Also, as patients are now discharged at their first or second postoperative visit, it would have been impossible to follow them up on a longitudinal basis for comparison.

We do not know why the AcrySof MA60BM lens should be more susceptible to these changes. Apart from the Allergan AR40 IOL, it is the only hydrophobic acrylic polymer implanted. Both of these IOLs have a much lower water content $(<1 \%)$ than the other acrylic IOLs (approximately 25\%) used. None of the Allergan IOLs showed evidence of deposits, but the sample number was small $(n=3)$. Acrylic copolymers can vary greatly from one IOL to another and the exact copolymer composition may have a bearing on the formation of these deposits. Of the IOLs implanted, the AcrySof MA60BM is the only one that is composed of a combination of polyethylacrylate and phenylethylmethacrylate. Even 5/18 (28\%) silicone lenses implanted showed some degree of these deposits.

We are unsure as to the exact nature of these deposits, but they resembled pigmentary deposits often seen on 
the surface of the optic of IOLs or on the corneal endothelium. In severe cases, they share some similarities with glistenings. We have been unable to explant any of these IOLs and further analyse them, as all patients are symptom free, alive and well. We initially postulated that this phenomenon was a result of iris pigment migration through the IOL. However, the number of IOLs with deposits and their degree of severity was not associated with those eyes that had undergone intraoperative manipulations of the iris, or with the degree of inflammation in the postoperative period. Therefore, there must be other mechanisms and factors involved in causing these changes related to the IOL biomaterial.

\section{Acknowledgements}

We thank Dr Peymane Adab, Department of Public Health and Epidemiology, The University of Birmingham, UK, for her assistance with the statistical analyses.

\section{References}

1 Hooper PL, Rao NA, Smith RE. Cataract extraction in uveitis patients. Surv Ophthalmol 1990; 35: 120-144.

2 O'Neill D, Murray PI, Patel BC, Hamilton AMP. Extracapsular cataract surgery with and without intraocular lens implantation in Fuchs' heterochromic cyclitis. Ophthalmology 1995; 21: 272-276.

3 Foster CS, Fong LP, Singh GS. Cataract surgery and intraocular lens implantation in patients with uveitis. Ophthalmology 1989; 96: 281-288.

4 Rauz S, Stavrou P, Murray PI. Evaluation of foldable intraocular lenses in patients with uveitis. Ophthalmology 2000; 107: 909-919.

5 Suresh PS, Jones NP. Phakoemulsification with intraocular lens implantation in patients with uveitis. Eye 2001; 15: 621-628.

6 Mondino BJ, Nagata S, Glovsky MM. Activation of the alternative complement pathway by intraocular lenses. Invest Ophthalmol Vis Sci 1985; 26: 905-908.

7 Mondino BJ, Rajacich GM, Sumner H. Comparison of complement activation by silicone intraocular lenses and polymethylmethacrylate intraocular lenses with polypropylene loops. Arch Ophthamol 1987; 105: 989-990.
8 Colman RW, Scott CF, Schmaier AH, Wachtfogel YT, Pixley RA, Edmunds LH Jr. Initiation of blood coagulation at artificial surfaces. Ann NY Acad Sci 1987; 516: 253-267.

9 Sievers H, von Domarus D. Foreign body reaction against intraocular lenses. Am J Ophthalmol 1984; 97: 743-751.

10 Majima K. An evaluation of the biocompatibility of intraocular lenses. Ophthalmic Surg Lasers 1996; 27: 946-951.

11 Jensen MK, Crandall AS, Mamalis N, Olson RJ. Crystallization on intraocular lens surfaces associated with the use of Healon GV. Arch Ophthalmol 1994; 112: 1037-1042.

12 Oslon RJ, Caldwell KD, Crandall AS, Jensen MK, Huang SC. Am J Ophthalmol 1998; 126: 177-184.

13 Davis DB. Crystallization reported in PMMA IOL. Ophthalmol Times 1993; 18: 1-2.

14 Parkin B, Pitts-Crick M. Opacification of silicone intraocular implant requiring lens exchange. Eye 2000; 14: 794-795.

15 Miyata A, Uchida N, Nakjima K, Yaguchi S. Clinical and experimental observation of glistening in acrylic intraocular lenses. J Jpn Ophthalmol Soc 2000; 104: 349-353.

16 Dhaliwal DK, Mamalis N, Olson RJ, Crandall AS, Zimmerman P, Alldredge OC. Visual significance of glistenings seen in the AcrySof intraocular lens. J Cataract Refract Surg 1996; 22: 452-457.

17 Dogru M, Tetsumoto K, Tagami Y, Kato T, Nakamae K. Optical and atomic force microscopy of an explanted AcrySof intraocular lens with glistening. J Cataract Refract Surg 2000; 26: 571-575.

18 Dick HB, Olson RJ, Augustin AJ, Schwenn O, Magdowski G, Pfeiffer N. Vacuoles in the AcrySof intraocular lens as factor of the presence of serum in aqueous humor. Ophthalmic Res 2001; 33: 61-67.

19 Omar O, Pirayesh A, Mamalis N, Olson RJ. In vitro analysis of AcrySof intraocular lens glistening in Acrypak and Wagon Wheel packaging. J Cataract Refract Surg 1998; 24: 107-113.

20 Christiansen G, Durcan FJ, Oslon RJ, Christiansen K. Glistenings in the AcrySof intraocular lens: pilot study. J Cataract Refract Surg 2001; 27: 728-733.

21 McKibbin M, Seemongal-Das R, Atkinson PL. Transient fogging of acrylic (AcrySof) intraocular lenses. Eye 1999; 13: 672-673.

22 Chang BYP, Davey KG, Gupta M, Hutchinson C. Late clouding of an acrylic intraocular lens following routine phakoemulsification. Eye 1999; 13: 807-808.

23 Sharma TK, Chawdhary S. The opalescence of hydrogel intraocular lens. Eye 2001; 15: 97-98.

24 House P, Barry C, Morgan W, Sumner C. Postoperative deposits on the AcrySof intraocular lens. Aust NZ J Ophthalmol 1999; 27: 301-305.

25 Lumme P, Laatikainen L. Cell reaction and pigment deposits on the posterior chamber intraocular lens. Acta Ophthalmol 1994; 72: 16-20. 